\title{
Cutaneous Metastasis: A Study of 138 Cases Diagnosed by Fine-Needle Aspiration Cytology
}

\author{
Uma Handa $^{\mathrm{a}}$ Reetu Kundu ${ }^{\mathrm{a}}$ Kislay Dimri ${ }^{\mathrm{b}}$ \\ Departments of a Pathology and ${ }^{b}$ Radiotherapy and Oncology, Government Medical College and Hospital, \\ Chandigarh, India
}

\author{
Keywords \\ Metastasis · Cutaneous · Skin · Cytomorphology · \\ Fine-needle aspiration cytology
}

\begin{abstract}
Background: Cutaneous metastases can occur in a wide variety of internal malignancies and may be the first sign of a clinically silent visceral cancer. Study Design: A retrospective analysis was made of 138 cases diagnosed with cutaneous and subcutaneous metastasis on fine-needle aspiration cytology (FNAC). Primary tumors of the skin/subcutis were excluded. Results: Of 138 cases, the primary was known in 101 cases and unknown in 37 cases. The age of the patients ranged from 5 to 86 years, and 76 (55.1\%) were male and 62 (44.9\%) were female. Clinically, the most common lesion was a single nodule ( $n=77,55.8 \%$ ). The chest wall was the predominant site ( $n=53,38.4 \%)$. In males and females, the most common primary sites were the lung $(n=16)$ and breast ( $n=24)$, respectively. On cytology, the most common diagnosis was metastatic adenocarcinoma ( $n=41,29.7 \%)$. Of 37 cases with an unknown primary, FNAC helped to locate the primary site in 17 (45.9\%) cases, while in 20 cases it remained undiagnosed. Conclusions: FNAC is a rapid and safe technique that can be used as a first line of investigation for con-
\end{abstract}

firmation of metastatic lesions of the skin. Critical evaluation of cytomorphological features along with relevant clinical details could help in the localization of an unknown primary site in some cases.

C) 2016 S. Karger AG, Basel

\section{Introduction}

Cutaneous metastasis in visceral cancers portends a poor prognosis and often is a hallmark of a widely spread malignancy [1]. Skin metastases occur rarely in patients with an underlying malignancy and have a frequency ranging from 0.8 to $5 \%$ [2]. The incidence of cutaneous metastasis increases with age and more so after the fifth decade of life [3]. Primary malignancies of the breast, lung, and gastrointestinal tract have a greater propensity to metastasize to the skin [4].

Most cutaneous metastases are seen in patients with a known primary; however, these may be the first clinical manifestation of an occult primary tumor [5]. Often cutaneous metastases go unrecognized clinically as they may be mistaken for certain dermatological conditions. A high index of clinical suspicion is required for an early diagnosis to enable prompt treatment.

\section{KARGER}

(c) 2016 S. Karger AG, Basel

E-Mail karger@karger.com

www.karger.com/acy
Correspondence to: Dr. Reetu Kundu

Department of Pathology, Government Medical College and Hospital Sector 32-A

Chandigarh 160030 (India)

E-Mail reetukundu@gmail.com 
Fine-needle aspiration cytology (FNAC) has been underutilized in routine dermatology practice, and even more so in the diagnosis of metastatic skin lesions. It is a minimally invasive, rapid, and cost-effective modality. In cases with a known primary tumor, the cytologic diagnosis of cutaneous metastasis is straight forward. However, in cases of unknown primary tumor, tumor typing and cytologic distinction between primary adnexal tumors and metastases to the skin presents a diagnostic dilemma. The present study was undertaken to establish the role of FNAC in diagnosing metastases to the skin irrespective of the primary tumor status.

\section{Materials and Methods}

The present retrospective study was conducted on 138 patients diagnosed with cutaneous and subcutaneous metastasis on FNAC between January 2004 and December 2013. Records of all patients were retrieved and reviewed for pertinent clinical history, examination findings, a diagnosed primary tumor, and details of other investigations performed. Patients with tumor recurrence at the site of previous surgery and those diagnosed as primary adnexal tumors were excluded from the study.

FNA was performed by standard technique using a 22- to $23-\mathrm{G}$ needle attached to a $10-\mathrm{mL}$ disposable syringe fitted onto a Franzen handle. Two to 3 passes were taken to obtain adequate material and 3-6 slides were prepared. Five patients underwent a repeat aspiration to obtain satisfactory material. Both wet and air-dried smears were made from the cytopuncture material. Air-dried smears were stained with May-Grünwald-Giemsa (MGG) stain. Wet smears were stained with hematoxylin and eosin (HE) and Papanicolaou (PAP) stains. Special stains like mucicarmine and periodic acid Schiff (PAS) were used whenever required. However, immunostains could not be performed.

\section{Results}

The present retrospective analysis included 138 cases diagnosed with cutaneous and subcutaneous metastases from visceral malignancies. Of 138 patients, the primary tumor was known in 101 cases (Table 1). In the other 37 cases the cutaneous deposit was the first manifestation of an unknown primary. The age of the patients ranged from 5 to 86 years, and there were $76(55.1 \%)$ males and 62 (44.9\%) females.

Clinically, the most common lesion was a single nodule, which was seen in $77(55.8 \%)$ cases, multiple nodular lesions occurred in 33 (23.9\%), plaque lesions in 8 (5.8\%), and large firm to cystic lesions in $20(14.5 \%)$ cases. The lesions were solid to cystic, ranging from $<1$ to $8.5 \mathrm{~cm}$ and were soft to hard in consistency. Surface ulceration was seen in 3 cases. The chest wall was the predominant site involved in 53 (38.4\%) cases, followed by the abdominal wall, including the paraumbilical region in 33 (23.9\%) and head and neck in 21 (15.2\%). Nine cases had involvement in multiple sites.

\section{Cases with Known Primary Tumor}

Of 101 cases with a known primary, the most common primary site of tumor was the breast ( 24 cases). In males, lung cancer (Fig. 1a) was the most common primary site (12 cases) followed by hematolymphoid malignancy ( 9 cases) and the colon (5 cases). In females, the most common cancer to metastasize to the skin was breast carcinoma (23 cases), followed by carcinoma of the gallbladder and the ovary ( 5 cases each).

On cytologic examination of metastatic tumor deposits, the most common morphologic diagnoses rendered were adenocarcinoma in 26 cases, infiltrating ductal carcinoma in 23 (Fig. 1b), squamous cell carcinoma (SCC) in 22, non-Hodgkin lymphoma (NHL) in 10, and renal cell carcinoma (RCC) (Fig. 1c) in 3 cases. The smears in cases of metastatic adenocarcinoma showed clusters of tumor cells with a high $\mathrm{N}: \mathrm{C}$ ratio, vesicular nuclei, conspicuous nucleoli, and a moderate to ample amount of vacuolated cytoplasm. In SCC, scattered and cohesive tumor cells with hyperchromatic nuclei and dense basophilic cytoplasm were observed. Cases with NHL showed monomorphic atypical lymphoid cells with pale/vesicular nuclei, small to large nucleoli, irregular nuclear contours at places, and a scanty to moderate amount of cytoplasm. Areas of necrosis were also observed in some cases with high-grade NHL. Aspirate smears in RCC were cellular, showing loosely cohesive clusters of tumor cells with invariably uniform nuclei, inconspicuous to visible nucleoli, and plentiful vacuolated to granular fragile cytoplasm. Strands of stromal material and endothelial cells could be appreciated in some cases. These features of metastatic tumors correlated with the histopathological features of the primary tumor.

There were 2 cases each of mucoepidermoid carcinoma of the parotid gland (Fig. 1d), medullary carcinoma of thyroid (Fig. 2a), and small cell carcinoma of the lung. There was 1 case each of transitional cell carcinoma, seminoma, granulosa cell tumor, clear cell sarcoma, osteosarcoma (Fig. 2b), leiomyosarcoma (Fig. 2c), and melanoma. Of 4 cases with bone marrow as the primary site, the cytologic diagnoses correlated with the hematologic diagnoses of acute myeloid leukemia in 2 cases, and multiple myeloma and NHL (Fig. 2d) in 1 case each. 
Table 1. Cutaneous and subcutaneous metastases in patients with a known primary malignancy $(n=101)$

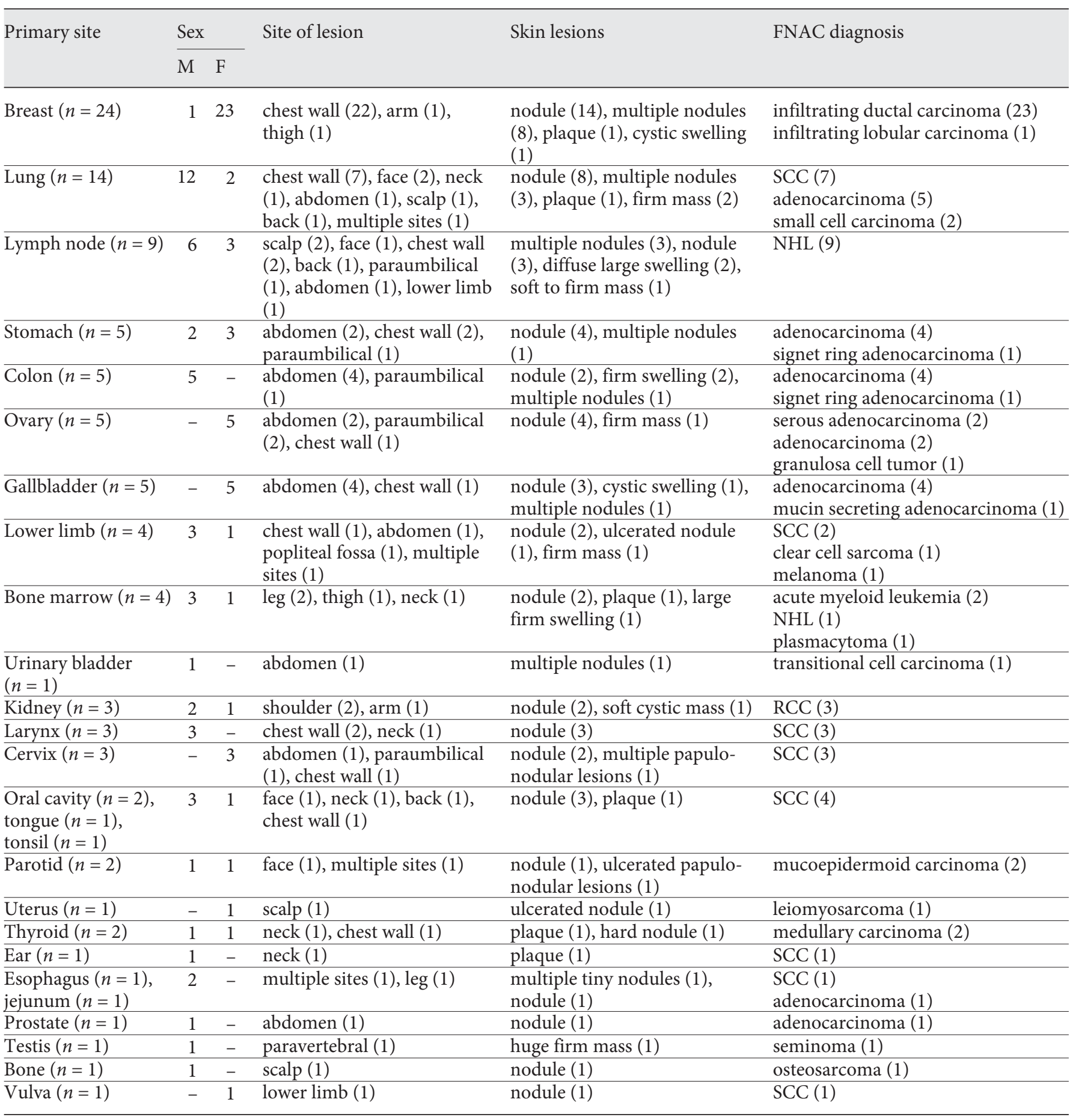


Fig. 1. a Cutaneous metastasis in the chest wall from a lung carcinoma showing features of SCC. PAP stain. $\times 400$. b Metastasis to the chest wall from a breast carcinoma showing features of infiltrating ductal carcinoma. MGG stain. $\times 400$. c Aspirate showing clusters of tumor cells with round nuclei and abundant cytoplasm with vacuolations in metastasis from RCC. MGG stain. $\times 400$. d FNA smear showing clusters of tumor cells, some containing cytoplasmic mucin vacuoles in metastatic mucoepidermoid carcinoma. MGG stain. $\times 400$. Inset Mucous cells with cytoplasmic positivity on mucicarmine staining. Mucicarmine stain. $\times 400$.

Fig. 2. a Cellular aspirate showing loosely cohesive clusters and scattered tumor cells with a plasmacytoid appearance and occasional binucleation in cutaneous metastasis from medullary thyroid carcinoma. HE stain. $\times 400$. $\mathbf{b}$ Aspirate from a scalp nodule in osteosarcoma showing highly pleomorphic malignant cells. MGG stain. $\times 400$. c Aspirate from metastatic leiomyosarcoma showing spindle-shaped tumor cells in a syncytium. HE stain. $\times 400$. d FNA smear in NHL showing dispersed monotonous atypical lymphoid cells with fine homogeneous chromatin and scant cytoplasm. MGG stain. $\times 400$.
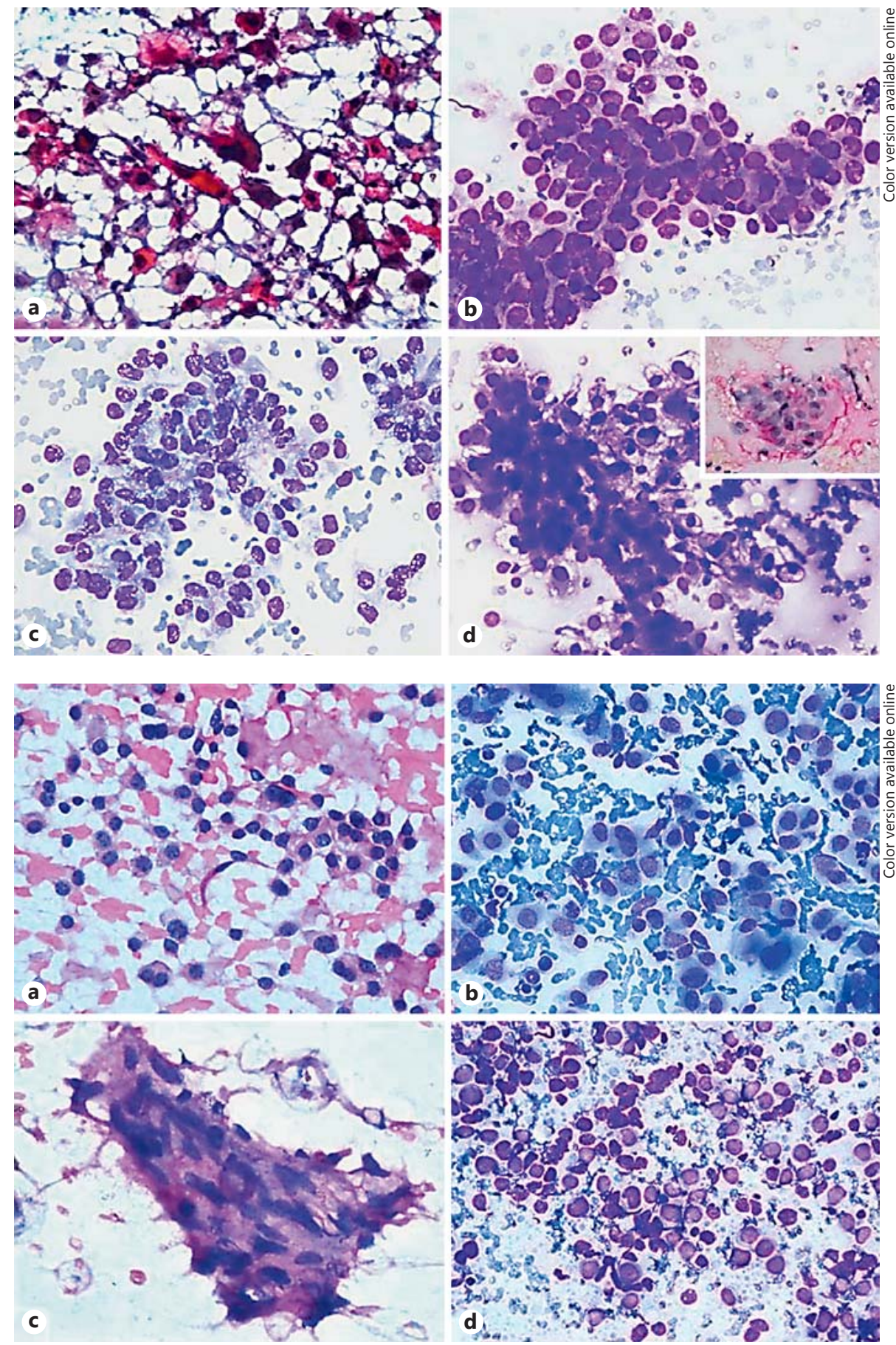

\section{Cases with Unknown Primary Tumor}

Thirty-seven out of 138 cases presented with cutaneous metastases as the first sign of a clinically silent visceral cancer. In this group the most common site for a cutaneous metastasis was the chest wall (12) followed closely by the abdominal wall (9). Multiple-site involve- ment was seen in 5 cases. Following the FNAC it was possible to locate the primary site in 17 cases (Table 2). In these 17 cases, the cytomorphologic diagnoses given were adenocarcinoma (6), poorly differentiated carcinoma (3), metastatic carcinoma favoring SCC (2), RCC (2), hepatocellular carcinoma (1), small cell carcinoma (1), malig- 
Table 2. Patients with primary tumor diagnosed subsequent to cutaneous metastasis $(n=17)$

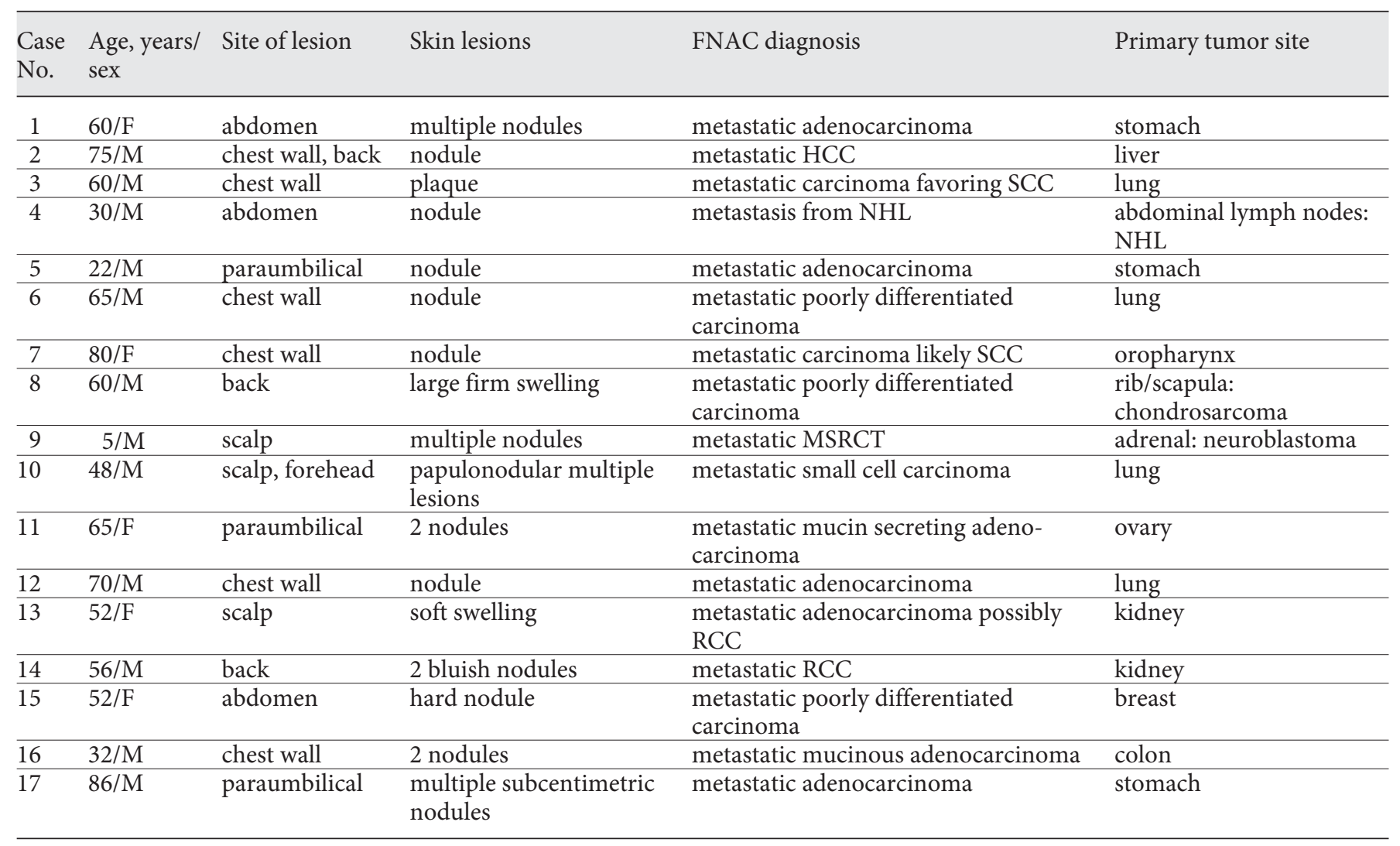

MSRCT, malignant small round cell tumor.

nant small round cell tumor (1), and NHL (1). In some cases, certain cytomorphological features were observed that could help to suggest the possible site of primary tumor. Cellular aspirates with clusters of tumor cells having a low N:C ratio, uniform round nuclei, and finely vacuolated cytoplasm favored a renal primary. Moderately cellular smears with tumor cells forming vague acinar patterns with a high $\mathrm{N}: \mathrm{C}$ ratio, prominent nucleoli, and the presence of intracytoplasmic bile pigment pointed towards the liver as the primary tumor site. Finally, following the FNA diagnosis, the definite primary site could be located with the help of other diagnostic modalities.

In 20 cases the primary site of malignancy remained undetected as the patients did not accept further investigations or were lost to follow-up (Table 3 ). The cytomorphologic diagnosis rendered in these 20 cases included adenocarcinoma (8 cases), poorly differentiated carcinoma (7), metastatic carcinoma favoring SCC (3), neuroendocrine carcinoma (1), and NHL (1).

\section{Discussion}

Cutaneous metastasis from visceral cancers regardless of the histotype or the organ of primary malignancy usually represents a diffuse metastatic disease with a dismal prognosis [6]. Early detection of metastasis to the skin is essential to initiate appropriate treatment and recent advances in chemotherapeutic regimes have shown increased survival [7]. FNAC is a preferred preliminary modality in suspected cases of cutaneous metastasis which obviates the need for other invasive diagnostic procedures [8].

The source of primary tumor responsible for cutaneous deposits differs in males and females [5]. In males, the common sites of primary tumor are the lung, colon, and oral cavity. In our study, lung carcinoma was the most common primary site in males. In females, metastasis to the skin is commonly seen in breast carcinoma, followed by the ovary, colon, and lung. In the present 
Table 3. Cutaneous and subcutaneous metastases in patients with an unknown primary tumor $(n=20)$

\begin{tabular}{|c|c|c|c|c|c|}
\hline $\begin{array}{l}\text { Case } \\
\text { No. }\end{array}$ & $\begin{array}{l}\text { Age, } \\
\text { years/sex }\end{array}$ & Site of lesion & Skin lesions & Cytologic diagnosis & $\begin{array}{l}\text { Deposits at } \\
\text { other sites }\end{array}$ \\
\hline 1 & $60 / \mathrm{F}$ & $\begin{array}{l}\text { back, abdomen, } \\
\text { chest wall }\end{array}$ & single nodule & metastatic adenocarcinoma & none \\
\hline 2 & $22 / \mathrm{M}$ & $\begin{array}{l}\text { chest wall, scalp, } \\
\text { lower limbs }\end{array}$ & $\begin{array}{l}\text { multiple papulonodular } \\
\text { lesions }\end{array}$ & metastatic neuroendocrine carcinoma & none \\
\hline 3 & $48 / \mathrm{F}$ & abdomen & multiple nodules & metastatic adenocarcinoma & none \\
\hline 5 & $60 / \mathrm{M}$ & chest wall & multiple nodules & metastatic adenocarcinoma & $\begin{array}{l}\text { right kidney, } \\
\text { bilateral lungs }\end{array}$ \\
\hline 6 & $50 / \mathrm{M}$ & forehead & nodule & metastatic poorly differentiated carcinoma & liver \\
\hline 7 & $55 / \mathrm{F}$ & chest wall & plaque & metastatic poorly differentiated carcinoma & none \\
\hline 8 & $25 / \mathrm{M}$ & paraumbilical & nodule & deposits from mucin secreting adenocarcinoma & liver \\
\hline 9 & $50 / \mathrm{M}$ & left shoulder & large firm swelling & $\begin{array}{l}\text { metastatic poorly differentiated carcinoma } \\
\text { possibilities: SCC, urothelial }\end{array}$ & $\begin{array}{l}\text { lytic lesion left } \\
\text { humerus }\end{array}$ \\
\hline 13 & $70 / \mathrm{M}$ & chest wall & nodule & metastatic poorly differentiated carcinoma & none \\
\hline 14 & $32 / \mathrm{M}$ & chest wall, forearm & multiple nodules & metastatic poorly differentiated adenocarcinoma & brain \\
\hline$\overline{15}$ & $60 / \mathrm{M}$ & infraorbital & $\begin{array}{l}\text { erythematous soft cystic } \\
\text { swelling }\end{array}$ & metastatic carcinoma favoring SCC & $\begin{array}{l}\text { erosion into left } \\
\text { maxillary sinus }\end{array}$ \\
\hline 16 & $62 / \mathrm{M}$ & chest wall & nodule & metastatic carcinoma likely squamous & rib erosion \\
\hline 17 & $70 / \mathrm{F}$ & chest wall & multiple nodules & poorly differentiated adenocarcinoma & none \\
\hline 18 & $75 / \mathrm{M}$ & chest wall & nodule & metastatic poorly differentiated carcinoma & none \\
\hline 19 & $40 / \mathrm{M}$ & chest wall & large mass & metastatic poorly differentiated carcinoma & none \\
\hline 20 & $49 / \mathrm{M}$ & neck & nodule & metastatic carcinoma likely squamous & none \\
\hline
\end{tabular}

study, breast cancer was also the most common site of primary tumor.

Cutaneous metastasis may occur by direct extension, local invasion through lymphatics/body cavities, or distant metastasis via the hematogenous or lymphatic route [9-12]. The complex molecular mechanisms responsible for tumoral metastasis to the skin are not completely understood. It is believed that certain chemokines and their receptors have a role to play [13]. Interactions between dermal/epidermal factors and tumor cells have a plausible role in the skin-homing mechanism of neoplastic cells [11].

The common sites of cutaneous/subcutaneous metastases are the scalp, abdomen, and chest, followed by the back and extremities [6]. In metastases from an unknown primary, the abdominal wall is the most preferred site [2]. In the present study, the chest wall was the most common metastatic site followed by the abdominal wall. The pattern of spread is related to the mode of dissemination and the anatomic proximity of the primary neoplasm [1416]. Lung and breast cancer commonly metastasize to the chest wall. The abdominal wall is a favored site for the primary from the gastrointestinal tract [17]. Tumors of renal origin have a predilection for the back. Thus, the site of skin metastasis can help suggest a possible organ of origin.

Most cutaneous metastases appear as mobile solitary or multiple, flesh-colored dermal or subcutaneous nodules which are variable in size and are usually painless [5, $10,18]$. Other presentations include telangiectatic violaceous papulovesicles, alopecia neoplastica, nonulcerative papules, erythematous-infiltrating plaques, and zosteriform metastasis [5]. Some malignancies may have peculiar metastatic nodules, such as pulsatile red/purple-colored nodules in RCC [19] and blanchable bluish nodules in neuroblastoma [20].

Among various tumors, carcinomas have increased in propensity for cutaneous metastases. Melanomas, hematolymphoid malignancies, germ cell tumors, and rarely sarcomas can also metastasize to the skin [5]. Ewing sarcoma, osteosarcoma, leiomyosarcoma, epithelioid sarcoma, chondrosarcoma, and angiosarcoma have been re- 
ported with skin metastasis [21-24]. In the current study, single cases of leiomyosarcoma and osteosarcoma were reported.

Clinically, cutaneous metastases may mimic primary adnexal tumors. On cytology, the distinction between primary adnexal tumors and cutaneous metastases can be made by morphologic features, histochemical stains, and immunostains. Primary adnexal tumors with a clear cell morphology like sebaceous neoplasms or clear cell hidradenoma can mimic metastatic RCC or a clear cell variant of SCC [25]. Tumor cells showing a PAS-positive diastase-sensitive reaction indicate renal origin. Evidence of squamous differentiation, orangeophilia on PAP stain, and a negative fat stain using oil red $\mathrm{O}$ are pointers towards SCC. Primary adnexal carcinoma with sweat gland derivation can mimic metastatic adenocarcinoma. Distinguishing between primary cutaneous mucinous carcinoma and metastatic mucinous adenocarcinoma is a challenge. Morphological features such as 3-dimensional papillae, pools of extracellular mucin, and signet cells are fairly reliable indicators of metastasis [17].

In cases of cutaneous metastasis with an unknown primary, the aim of cytologic diagnosis is to identify the site of primary tumor. The use of immunostains may help to suggest the possible primary site in cases with an unknown primary tumor, and also plays a role in confirming the known previous malignancy. Immunocytochemistry can be conducted on air-dried aspirate smears or cell blocks made from the aspirated material [26]. The use of a single immunomarker does not usually help to point to a specific organ, for example, hormone receptors can be positive in the breast, ovary, and uterine endometrium [27]. Various working algorithms involving panels of immunostains have been recommended. The primary panel comprising of CK, S-100, vimentin, and LCA may be followed for determining the tumor cell lineage. Depending on the results, further panels can be employed. Immunopanels with up to 10 markers to determine the primary site in metastatic adenocarcinoma employing CDX2, CK7, CK20, TTF-1, CEA, MUC2, MUC5AC, SMAD4, ER, and GCDFP-15 have been advocated [28]. Nevertheless, immunomarkers are neither $100 \%$ specific nor $100 \%$ sensitive. A combination of cytomorphological findings with ancillary immunocytochemistry and other clinical diagnostic workup with close collaboration between the cytologist and the treating clinician holds the key.

To conclude, metastatic cutaneous lesions bearing therapeutic and prognostic implications are amenable to early visual detection. FNAC can be used as a first line of investigation for the confirmation of metastatic lesions to the skin. Critical evaluation of cytomorphological features, along with relevant clinical details and immunocytochemistry, can help to identify an unknown primary, and also confirm the known previous malignancy.

\section{Disclosure Statement}

The authors have no conflicts of interest to report in relation to this work.

\section{References}

1 Alcaraz I, Cerroni L, Rütten A, Kutzner H, Requena L: Cutaneous metastases from internal malignancies: a clinicopathologic and immunohistochemical review. Am J Dermatopathol 2012;34:347-393.

2 Bansal R, Patel T, Sarin J, Parikh B, Ohri A, Trivedi P: Cutaneous and subcutaneous metastases from internal malignancies: an analysis of cases diagnosed by fine needle aspiration. Diagn Cytopathol 2011;39:882-887.

3 Rolz-Cruz G, Kim CC: Tumor invasion of the skin. Dermatol Clin 2008;26:89-102.

4 El Khoury J, Khalifeh I, Kibbi AG, Abbas O: Cutaneous metastasis: clinicopathological study of 72 patients from a tertiary care center in Lebanon. Int J Dermatol 2014;53:147-158.

5 Hussein MR: Skin metastasis: a pathologist's perspective. J Cutan Pathol 2010;37:e1-e20.

6 Aldret S, Cotton L: Skin as a site of metastasis. Osteopath Fam Phys 2012;4:13-17.
7 Schoenlaub P, Sarraux A, Grosshans E, Heid E, Cribier B: Survival after cutaneous metastasis: a study of 200 cases. Ann Dermatol Venereol 2001;128:1310-1315.

8 Handa U, Garg S, Mohan H: Fine-needle aspiration cytology of Sister Mary Joseph's (paraumbilical) nodules. Diagn Cytopathol 2008;36:348-350.

9 Leonard N: Cutaneous metastases: where do they come from and what can they mimic? Curr Diagn Pathol 2007;13:320-330.

10 Fernández-Antón Martínez MC, Parra-Blanco V, Avilés Izquierdo JA, Suárez Fernández RM: Cutaneous metastases of internal tumors. Actas Dermosifiliogr 2013;104:841853.

11 Wollina U, Graefe T, Konrad H, Schönlebe J, Koch A, Hansel G: Cutaneous metastases of internal cancer. Acta Dermatoven APA 2004; 3:79-84.
12 Pak HY, Foster BA, Yokota SB: The significance of cutaneous metastasis from visceral tumors diagnosed by fine-needle aspiration biopsy. Diagn Cytopathol 1987;3:24-29.

13 Avgerinou G, Flessas I, Hatziolou E, Zografos G, Nitsios I, Zagouri F: Cutaneous metastasis of signet-ring gastric adenocarcinoma to the breast with unusual clinicopathological features. Anticancer Res 2011;31:2373-2378.

$14 \mathrm{Hu}$ SC, Chen GS, Wu CS, Chai CY, Chen WT, Lan CC: Rates of cutaneous metastases from different internal malignancies: experience from a Taiwanese medical center. J Am Acad Dermatol 2009;60:379-387.

15 Saeed S, Keehn CA, Morgan MB: Cutaneous metastasis: a clinical, pathological, and immunohistochemical appraisal. J Cutan Pathol 2004;31:419-430. 
16 Srinivasan R, Ray R, Nijhawan R: Metastatic cutaneous and subcutaneous deposits from internal carcinomas: an analysis of cases diagnosed by fine needle aspiration. Acta Cytol 1993;37:894-898.

17 Sharma S, Kotru M, Yadav A, Chugh M, Chawla A, Makhija M: Role of fine-needle aspiration cytology in evaluation of cutaneous metastases. Diagn Cytopathol 2009;37:876880.

18 Sittart JA, Senise M: Cutaneous metastasis from internal carcinomas: a review of 45 years. An Bras Dermatol 2013;88:541-544.

19 Porter NA, Anderson HL, Al-Dujaily S: Renal cell carcinoma presenting as a solitary cutaneous facial metastasis: case report and review of the literature. Int Semin Surg Oncol 2006; $3: 27$.
20 Bodemer C, Dubois M, Droz D, Zucker R, de Prost Y: Congenital cutaneous metastasis of neuroblastoma. Ann Dermatol Venereol 1990;117:798-800.

21 Biswas G, Khadwal A, Kulkarni P, Bakshi A, Nair C, Kurkure P, et al: Ewing's sarcoma with cutaneous metastasis - a rare entity: report of three cases. Indian J Dermatol Venereol Leprol 2005; 71:423-425.

22 Collier DA, Busam K, Salob S: Cutaneous metastasis of osteosarcoma. J Am Acad Dermatol 2003;49:757-760.

23 Tomasini D, Niccoli A, Crivelli F, Scandroglio I: Cutaneous scalp metastasis as the first indication of a clinically silent retroperitoneal leiomyosarcoma and of its further relapse as metastatic widespread disease. Eur J Dermatol 2014;24:264-265.

24 Arce FP, Pinto J, Portero I, Echevarría S, ValBernal JF: Cutaneous metastases as initial manifestation of dedifferentiated chondrosarcoma of bone: an autopsy case with review of the literature. J Cutan Pathol 2000;27:262267.
25 Perna AG, Prieto VG, Lazar AJF, Ivan D: Primary cutaneous adnexal neoplasms and their metastatic look-alikes. Pathol Case Rev 2007; 12:61-69.

26 Gupta RK, Naran S: Fine needle aspiration cytology of cutaneous and subcutaneous metastatic deposits from epithelial malignancies: an analysis of 146 cases. Acta Cytol 1999;43: 126-130.

27 Kandalaft PL, Gown AM: Practical applications in immunohistochemistry: carcinomas of unknown primary site. Arch Pathol Lab Med 2016;140:508-523.

28 Park SY, Kim BH, Kim JH, Lee S, Kang GH: Panels of immunohistochemical markers help determine primary sites of metastatic adenocarcinoma. Arch Pathol Lab Med 2007; 131:1561-1567. 